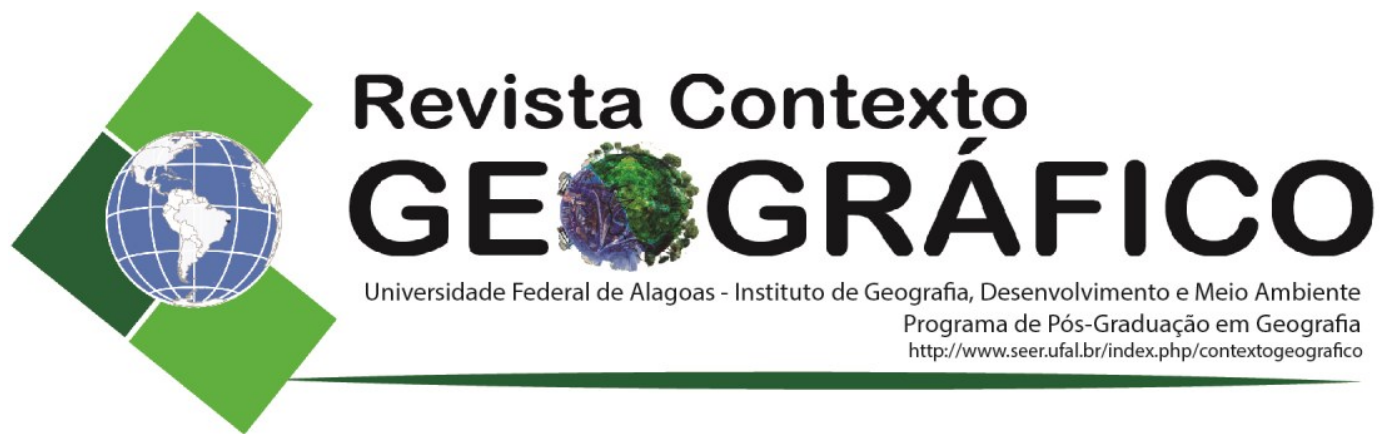

\title{
OS PARADIGMAS DA SUSTENTABILIDADE: ENTRE O ECODESENVOLVIMENTO E O DESENVOLVIMENTO SUSTENTÁVEL
}

\author{
Kássia Karina Silva de Araújo \\ Universidade Federal de Alagoas, Pós-Graduação em Geografia, Maceió, AL, Brasil \\ Kassia.s.araujo@hotmail.com
}

Carlos Maurício Rocha Barroso

Universidade Federal de Alagoas, Instituto de Geografia, Desenvolvimento e Meio Ambiente,

Maceió, AL, Brasil

cmrb@igdema.ufal.br

Éder Júnior Cruz de Souza

Instituto Federal de Alagoas, Marechal Deodoro, AL, Brasil

edergeografia@hotmail.com

\begin{abstract}
RESUMO - O presente trabalho apresenta os paradigmas da sustentabilidade, um confronto entre os conceitos de Ecodesenvolvimento e Desenvolvimento Sustentável sob a óptica de vários autores. Apesar de serem considerados sinônimos, os conceitos de Ecodesenvolvimento e Desenvolvimento Sustentável se diferenciam a partir de sua abrangência e do ponto de vista da sustentabilidade que se quer alcançar. O próprio conceito de Desenvolvimento Sustentável gera controvérsia entre autores que defendem que Sustentabilidade e Desenvolvimento Econômico não caminham juntos, além de ser um conceito generalizado, que parte do global para o local, enquanto que o conceito de Ecodesenvolvimento parte das potencialidades ambientais, culturais e econômicas do local para alcançar a Sustentabilidade. Por fim, o objetivo não é dizer qual conceito é certo ou errado, mas sim, despertar no leitor o interesse em discutir os conceitos ampliar o campo de conhecimento através das indagações.
\end{abstract}

Palavras-chave: Gestão ambiental; Meio ambiente; Desenvolvimento local.

\section{THE PARADIGMS OF SUSTAINABILITY: BETWEEN ECODEVELOPMENT AND SUSTAINABLE DEVELOPMENT}

\begin{abstract}
This work presents the paradigms of sustainability, a confrontation between the concepts of Ecodevelopment and Sustainable Development from the perspective of several authors. Although they are considered synonyms, the concepts of Ecodevelopment and Sustainable Development differ from their scope and the point of view of the sustainability that one wants to achieve. The concept of Sustainable Development itself raises controversy among authors who argue that sustainability and economic development do not go together, as well as being a generalized concept that goes from the global to the local, while the concept of Ecodevelopment starts from the environmental, cultural and economic potentialities to achieve Sustainability. Finally, the objective is not to say which concept is right or wrong, but rather to awaken in the reader the interest in discussing the concepts to broaden the field of knowledge through inquiries
\end{abstract}

Keywords: Environmental management; Environment; Local development.

\section{INTRODUÇÃO}

Por várias vezes os termos Ecodesenvolvimento e Desenvolvimento Sustentável são usados como sinônimos, porém há uma diferença entre os dois conceitos. Foram às várias 
discussões acerca do conceito de Ecodesenvolvimento que ocasionaram, de forma preparatória, a posterior adoção do conceito de Desenvolvimento Sustentável, estes se diferenciam pelo fato de que o Ecodesenvolvimento surgiu como um modelo alternativo para a política do desenvolvimento, sendo conceituado como um estilo de desenvolvimento de um país ou região baseado nas suas próprias potencialidades.

Já o conceito de Desenvolvimento Sustentável parece ter nascido sob um signo de contradição, o qual pode ser observado através de uma consulta ao mais popular dicionário da língua portuguesa, que em seus verbetes trás as seguintes definições: desenvolvimento [ato ou efeito de desenvolver, crescimento, progresso] e; sustentabilidade [conservar; manter; alimentar] (FERREIRA, 2000).

Devido à polêmica contradição de palavras, tal conceito não tem uma definição concreta, podendo variar de autor para autor e do ponto de vista dos mesmos em relação aos instrumentos necessários para o desenvolvimento econômico e a conservação do meio ambiente.

O conceito mais conhecido de Desenvolvimento Sustentável é do Relatório Brundtland também conhecido como "Nosso Futuro Comum", elaborado pela Comissão Mundial sobre Meio Ambiente e Desenvolvimento, que define Desenvolvimento Sustentável como o encontro entre as necessidades do presente, sem comprometer a possibilidade das futuras gerações em encontrar recursos que satisfaçam suas necessidades (GUARAGNI, 2010).

O trabalho tem como objetivo apontar os conceitos de Ecodesenvolvimento e Desenvolvimento Sustentável, e consequentemente diferenciá-lo. Como também, apontar autores que não concordam com as definições acerca do conceito de Desenvolvimento Sustentável.

Para isto realizou-se o levantamento de referenciais teóricos existentes, principalmente de autores que tratam da gênese e dos conceitos de Ecodesenvolvimento e Desenvolvimento Sustentável. Como também de autores que têm certa divergência com o conceito de Desenvolvimento Sustentável. Tais atividades foram desenvolvidas através de pesquisas em bibliotecas de instituições públicas, endereços eletrônicos, assim como em revistas e periódicos especializados.

\section{CONCEITOS E DIVERGÊNCIAS}

Antes de entrarmos no debate do conceito de desenvolvimento sustentável, torna-se essencial e indispensável entendermos, a priori, o conceito de desenvolvimento, o qual vai bem além da mera multiplicação da riqueza material.

O conceito de desenvolvimento pode ser explicado com base em três diferentes definições:

1. Desenvolvimento como sinônimo de crescimento econômico, o que traz em si uma simplificação acerca de ambos os conceitos;

2. Desenvolvimento como uma simples ilusão, crença, mito, ou manipulação ideológica;

3. Desenvolvimento não deve ser simplificado ou igualado com crescimento econômico. (VEIGA, 2005)

Cada autor tem seu ponto e de vista e consequentemente seu conceito de desenvolvimento, sendo assim, é comum vermos os três modos de definição de desenvolvimento sendo discutidos por diferentes autores.

Para Furtado (1998), é possível alcançar o desenvolvimento quando a capacidade criativa do homem se volta para a descoberta de suas potencialidades, e ele se empenha em enriquecer o universo que o gerou. 
Sachs (2004) afirma que desenvolvimento é diferente de crescimento econômico, este último trata de uma condição necessária, mas não suficiente, para alcançar uma vida melhor; já o desenvolvimento trata de reparar as desigualdades, ou seja, a igualdade, equidade e solidariedade fazem parte do conceito de desenvolvimento ao longo prazo, diferenciando assim do economicismo sedutor.

Ainda segundo Sachs (2004), o conceito de desenvolvimento vem se aperfeiçoando com o passar dos tempos, deixando de ser uma mera análise do Produto Interno Bruto (PIB), tendo como objetivo maior a redução da pobreza, fenômeno vergonhoso para a sociedade que vive em um mundo de abundância.

Segundo Omena Neto (2010, p. 125) "há uma dissociação entre o "crescimento econômico" e o "desenvolvimento", isto facilmente identificável quando analisamos que um Estado ou região de grande produção de bens primários pode ter um PIB elevado, mas um Índice de Desenvolvimento Humano muito baixo".

Um exemplo claro da dissociação de "desenvolvimento" e "crescimento econômico" é o Estado de Alagoas, como interroga Omena Neto (2010):

\begin{abstract}
Tenta-se achar explicação para o caso de como nosso Estado, classificado como o $8^{\circ}$ produtor de energia elétrica em kW no país, conforme dados da ANP (2006), pode, no entanto, ser o $26^{\circ}$ colocado entre os estados da Federação, em relação ao Índice de Desenvolvimento Humano (IDH), de acordo com RDH/PNUMA (2006), ficando como penúltimo dos estados em relação a esse índice. Como se pode produzir um dos insumos mais importantes, e um dos mais caros, e permanecer em situação social tão degradante? (OMENA NETO, 2010, p. 126)
\end{abstract}

Apesar dos avanços metodológicos em relação aos cálculos do Índice de Desenvolvimento Humano, os resultados obtidos não mostram plenamente a realidade de um país, uma vez que se baseiam em resultados exclusivamente matemáticos. Assim, percebemos a necessidade dele ser completado por outros indicadores, como por exemplo: a inclusão social, a capacidade de participar das decisões que se referem à sociedade e o respeito dado pela mesma a um indivíduo. Pois mesmo sendo rico, saudável e instruído, sem esses direitos o desenvolvimento do indivíduo é limitado.

Já o conceito de sustentabilidade surgiu como uma resposta à preocupação sobre o desenvolvimento do mundo. O Grupo de Pesquisa FAE (apud GUARAGNI; CARON, 2010, p. 6) define o termo sustentabilidade como sendo "um processo de transformação que ocorre de forma harmoniosa nas dimensões: espacial, social, ambiental, cultura e econômica, a partir do indivíduo para o global".

Em 1987 o discurso acerca do conceito de sustentabilidade, começou a ganhar corpo com a publicação do estudo "Our Common Future", da United Nations Worl Commission on Environment and Development, que define Desenvolvimento Sustentável como "o encontro entre as necessidades do presente, sem comprometer a possibilidade das futuras gerações em encontar recursos que satisfaçam suas necessidades" (GUARAGNI; CARON, 2010, p. 5)

O documento "Nosso Futuro Comum" apresenta o crescimento econômico como uma necessidade estratégica, tanto dos países subdesenvolvidos quanto nos ditos desenvolvidos, para se fazer face ao desafio da pobreza no mundo (Comissão Mundial Sobre Meio Ambiente e Desenvolvimento apud Souza, 2005).

A noção de sustentabilidade implica numa necessária interpretação entre justiça social, qualidade de vida, equilíbrio ambiental com capacidade de suporte. Mas também se associa a uma premissa da garantia de sustentação econômico-financeira e institucional (JACOBI, 1999, p.43). 
Segundo Manegat e Almeida (2004) a sustentabilidade não é uma tecnologia a qual no passe de mágica salvará todos da degradação ambiental, ela é uma função cultural que deve abranger todas as atividades humanas: técnico-científica, econômica, jurídica, política, social, cultural e histórica.

Devido à contradição de palavras, o conceito de Desenvolvimento Sustentável altera de autor para autor e do seu ponto de vista em relação aos instrumentos necessários para o desenvolvimento econômico e a conservação do meio ambiente.

Por várias vezes o termo "Desenvolvimento Sustentável" foi confundido com o termo "Ecodesenvolvimento", porém o conceito de Ecodesenvolvimento surgiu da preocupação com a preservação do meio ambiente conjugada com a melhoria das condições socioeconômicas da população, e logo após foi substituído pelo conceito de Desenvolvimento Sustentável.

O termo Ecodesenvolvimento foi utilizado pela primeira vez por Maurice Strong, secretáriogeral da Conferência Mundial sobre o Meio Ambiente Humano, realizada pelas Nações Unidas em Estocolmo em 1972, também conhecida como "Conferência de Estocolmo", na caracterização de um modelo alternativo para a política do desenvolvimento, porém foi largamente difundido por Ignacy Sachs, a partir de 1974, o qual deu a formulação dos princípios básicos desta nova proposição de desenvolvimento, sendo:

a) satisfação das necessidades básicas;

b) a solidariedade com as gerações futuras;

c) a participação da população envolvida;

d) a preservação dos recursos naturais e do meio ambiente em geral;

e) a elaboração de um sistema garantindo emprego, segurança social e respeito a outras culturas;

f) os programas de educação (Sachs, 1986).

Ecodesenvolvimento significa o desenvolvimento de um país ou região baseado nas suas próprias potencialidades, ou seja, um desenvolvimento sem dependências externas, mantendo assim uma harmonia entre os objetivos sociais e econômicos concomitantemente com a gestão ecologicamente prudente dos recursos e do meio, e assim uma solidariedade sincrônica com o povo atual em relação com suas necessidades fundamentais e uma solidariedade diacrônica com as gerações futuras em relação à economia dos recursos naturais e a garantia da qualidade de vida (MONTIBELLER FILHO, 2004).

Sachs (1986), também define o ecodesenvolvimento como um estilo de desenvolvimento particularmente adaptado às regiões rurais do Terceiro Mundo, o que não significa não se poder estendê-lo às cidades. É um estilo de desenvolvimento que insiste nas soluções específicas dos problemas de cada ecorregião, levando em conta os dados ecológicos, culturais, as necessidades imediatas como também as de longo prazo.

Segundo o mesmo autor, as discussões acerca do conceito de Ecodesenvolvimento ocasionaram, de forma preparatória, para a posterior adoção do conceito de Desenvolvimento Sustentável, onde até hoje os dois termos são usados como sendo sinônimos, embora não sejam.

As várias discussões acerca do conceito de Ecodesenvolvimento, serviram para substanciar o conceito de Desenvolvimento Sustentável (DS). Esse novo conceito pressupõe um conjunto de sustentabilidade; estas podem ser sintetizadas no seguinte trinômio: eficiência econômica, eficácia social e ambiental. Quando esse trinômio é alcançado simultaneamente significa atingir, portanto, o desenvolvimento sustentável (MONTIBELLER FILHO, 2004). 
Para Barbieri (2005), atingir o Desenvolvimento Sustentável seria, portanto, a solução dos problemas ambientais, não só em relação à degradação do ambiente físico e biológico, mas também os problemas ambientais em dimensões sociais, políticas e culturais, como a pobreza e a exclusão social. O DS é, contudo, a referência comum entre autores que se dedicam ao estudo da inter-relação entre sociedade e meio ambiente (MONTIBELLER FILHO, 2004)

Dentre alguns conceitos de Desenvolvimento Sustentável, destacamos o de MATIAS e PINHEIRO:

Desenvolvimento Sustentável é o desenvolvimento de uma sociedade em todos os seus aspectos integrando este com a natureza sem agredi-la nem interferir em seu funcionamento (...). O Desenvolvimento Sustentável foi e continua sendo apresentado como uma proposta e tentativa de solucionar os problemas decorrentes da crise ambiental e do aumento de consciência dessa crise, (2008, p.141).

Já para Frey (2001, p. 2), “o desafio de Desenvolvimento Sustentável é, antes de tudo, um problema político e de exercício de poder, que coloca em pauta a questão das instituições políticoadministrativas, da participação e do processo político".

Para Pesci (apud MANEGAT; ALMEIDA 2004) o DS é uma sociedade de fluxos cíclicos, é ganhar consciência de que somente compreendendo as relações e organizando-as no caos, podemos fazer com que a sociedade em que vivemos, a realidade global e planetária possa diretamente sobreviver.

Desenvolvimento sustentável não significa somente a conservação dos nossos recursos naturais, mas sobretudo um planejamento territorial, das áreas urbanas e rurais, um gerenciamento dos recursos naturais, um controle e estímulo às práticas culturais, à saúde, alimentação e sobretudo qualidade de vida. (CARRERA, 2005, p. 7)

Conforme Cavalcanti (1995), o conceito de DS é uma alternativa para o crescimento econômico, pois desenvolvimento sustentável significa qualificar o crescimento e reconciliar o desenvolvimento econômico com a necessidade de preservar o meio ambiente.

Dentro das concepções de Desenvolvimento Sustentável, são apontadas três abordagens: econômica-liberal de mercado; ecológico tecnocrata de planejamento; e política de participação democrática (FREY, 2001).

A primeira abordagem, econômica-liberal de mercado, aposta na força de auto regulação do mercado, tal abordagem acredita que:

(...) a pressão de concorrência, crescimento econômico e prosperidade levariam automaticamente ao uso racional dos recursos naturais, ao progresso tecnológico e a novas necessidades de consumo compatíveis com as exigências do meio ambiente. (FREY, 2001, p.3)

A segunda abordagem, ecológico tecnocrata de planejamento, considera o Estado e suas instituições de regulação e de planejamento como instrumentos indispensáveis para garantir a prevalência do bem comum, "a atenção primordial é direcionada para a dimensão ecológica, isto é, a compatibilidade do desenvolvimento econômico com a preservação dos recursos naturais, e que logo deve torna-se alvo prioritário da intervenção estatal” (FREY, 2001, p.7). A preocupação primária dessa abordagem é a salvaguarda das bases naturais da vida socioeconômica e a "saúde ecológica da civilização humana".

A terceira abordagem diz respeito aos que "confiam na atuação e mobilização política da própria população e das organizações da sociedade civil dentro de uma abordagem política de participação democrática" (FREY, 2001, p.2). A abordagem política de participação democrática busca, antes de tudo, a introdução da opinião pública nas decisões democráticas, seja ela União, Estados, Municípios ou Distritos Federais. Mais precisamente nos países em 
desenvolvimento tal abordagem almeja antes de tudo a defesa da humanidade ou uma vida digna para todos, o que, como consequência, deveria propiciar também uma harmonia maior com a natureza (op cit).

A Conferência das Nações Unidas sobre o Meio Ambiente e Desenvolvimento (CNUMAD), também conhecida como Cúpula da Terra, ou Eco 92, realizada em 1992 no Rio de Janeiro, estabeleceram o DS como uma das metas a serem alcançadas pelo governo e sociedade em todo o mundo (DIAS, 2007). Tal conferência resultou em cinco documentos oficiais aprovados:

a) A declaração do Rio de Janeiro sobre o Meio Ambiente e Desenvolvimento;

b) A declaração de princípios para a gestão sustentável das florestas;

c) O convênio sobre a diversidade biológica;

d) O convênio sobre as mudanças climáticas e;

e) O Programa das Nações Unidas para o século XXI, mais conhecido como: Agenda 21. (BARBIERI, 2005).

De todos os conceitos, a Agenda 21 é o mais abrangente e constitui um programa internacional que estabelece parâmetros para que se obtenha o desenvolvimento sustentável nas suas vertentes econômicas, social e ambiental (DIAS, 2007).

Porém, o conceito mais aceitável de DS é o definido pelo Relatório Brundtland, de 1987, da Comissão Mundial sobre Meio Ambiente e Desenvolvimento, como já citado no início da discussão.

Apesar de serem considerados sinônimos, a diferença entre os conceitos de Ecodesenvolvimento e Desenvolvimento Sustentável segundo Maimon (apud MONTIBELLER FILHO, 2004 p. 53), reside no seguinte:

\footnotetext{
O primeiro volta-se ao atendimento das necessidades básicas das populações, através da utilização de tecnologias apropriadas a cada ambiente e partindo do mais simples ao mais complexo; o segundo enfatiza o papel de uma política ambiental, a responsabilidade com os problemas globais e com as futuras gerações (op. cit).
}

Segundo Montibeller Filho (2004, p.19) “O Desenvolvimento Sustentável é um conceito amplo e, devido a esta característica, permite apropriações diferenciadas e ideologizadas por segmentos sociais de interesse".

As diferentes noções de desenvolvimento ou mesmo de sustentabilidade, dificultam a realização de uma interpretação prática dos objetivos políticos formulados em torno da proposta de desenvolvimento sustentável. (CHAVES; RODRIGUES, 2006).

Há autores que não concordam com todas as abordagens técnicas voltadas para o DS, como é o caso de Souza (2005) que afirma que o discurso padrão de DS, não apenas não se fundamenta em uma teoria científica consistente, como também, não encerra nenhum avanço analítico enquanto abordagem do desenvolvimento como desafio social; de certo modo, esse discurso é uma expressão acabada de falência intelectual da contemporaneidade.

Do mesmo ponto de vista, Faladori (2001), afirma que soluções técnicas não são válidas, uma vez que:

As soluções para os problemas ambientais não são técnicas, como seriam se os problemas fossem de limites físicos. Ao contrário, as soluções são, em primeira instância, sociais. Somente depois de resolver as contradições sociais, as alternativas técnicas ganham sentido. (FALADORI, 2001, p. 137) 
Segundo o mesmo autor é impossível tentar implantar uma política de DS, quando o principal problema se encontra na sociedade, principalmente em suas atitudes, as quais são induzidas pelo sistema capitalista de consumo gerando as desigualdades sociais em todas as dimensões.

Trata-se então não só da necessidade da gestão dos recursos naturais, da economia e do poder público, mas também, da inter-relação entre as necessidades humanas e o meio ambiente circundante, ou seja:

O meio ambiente não existe como uma esfera desvinculada das ações, ambições e necessidades humanas, e tentar defendê-lo sem levar em conta os problemas humanos deu à própria expressão meio ambiente uma conotação de ingenuidade em certos círculos políticos. (BARBIERI, 2005, p.24)

Ainda segundo o autor, devemos considerar alguns problemas sociais da mesma forma em que analisamos problemas ambientais, pois ambos são relativamente importantes para o Desenvolvimento Sustentável.

(...) a pobreza, a exclusão social e o desemprego devem ser tratados como problemas planetários, tanto quanto a chuva ácida, o efeito estufa, a depleção da camada de ozônio e o entulho espacial que se acumula ano a ano. Questões como essas estão no cerne das novas concepções de sustentabilidade. (BARBIERI, 2005, p. 38)

Não se deve levar em conta apenas as soluções técnicas, é preciso discutir as relações sociais entre homem e a sociedade, e as relações ambientais entre o homem e a natureza. Não poderemos entender as relações ambientais sem antes entender as relações sociais. De acordo com FALADORI (2001, p. 206):

\footnotetext{
As relações sociais são as que se estabelecem entre os seres humanos a partir da forma como se distribuem os meios de produção (...) Trata-se das causas de fundo dos problemas ambientais. Causas nunca específicas, mais sempre essenciais, que se manifestam nas mais variadas relações técnicas e não se explicam a partir de uma análise de causalidade imediata.
}

Trata-se, portanto de como se dá a relação sociedade-meio ambiental, ou seja, as soluções dos problemas ambientais decorrem de como o homem, no seu papel de cidadão, se vê perante os problemas do meio ambiente circundante e se ele se percebe como parte desse meio, se seus modos de exploração de recursos são para satisfazer suas necessidades ou devido ao simples aumento na sua escala de consumo. Segundo Barbieri:

\footnotetext{
O aumento da escala de produção tem sido um importante fator que estimula a exploração dos recursos naturais e eleva a quantidade de resíduos. Há quem sustente que os povos que se sentem parte da natureza apresentam um comportamento mais prudente em relação ao meio ambiente e utilizam seus recursos com parcimônia. A concepção de um ser humano separado dos outros elementos da natureza talvez tenha sido de maior relevância para $\mathrm{o}$ aumento dos problemas ambientai. A crença de que a natureza existe para servir ao ser humano contribui para o estado de degradação ambiental que hoje se observa. Mas certamente foi o aumento da escala de produção e consumo que iria provocar os problemas que hoje conhecemos. (BARBIERI, 2006, p. 5)
}

A partir do momento que o ser humano não se vê como parte dos problemas ambientais, o mesmo não se perceberá como parte das soluções de tais problemas, jogando a responsabilidade para os outros, e nunca para si mesmo. Um exemplo claro disso é explicado por Barbieri (2006, p. 14) "As pessoas que afirmam que há gente em excesso no Planeta não costumam se incluir entre os que estão sobrando, de modo que suas propostas sempre se voltam contra os outros, os que não podem se defender". 
Às vezes, chega-se a pensar que DS devesse ser equivalente à reconstrução do paraíso perdido, porém, o acesso estrutural e crescentemente diferenciado dos indivíduos aos recursos necessários à satisfação de suas necessidades, compromete qualquer estratégia de desenvolvimento sustentável (SOUZA, 2005).

Trata-se, pois, segundo Rees (apud SOUZA, 2005) de uma "fixação no crescimento" onde o pensamento corrente da maioria da população, o mainstream, se caracteriza por uma tensão escamoteada e disfarçada entre dois objetivos meramente contraditórios: o crescimento econômico e a proteção ambiental.

O mainstream das estratégias de sobrevivência está mudando não pela preocupação com a sustentabilidade, mas sim, pela pouca capacidade de sedução que as atividades insustentáveis estão tendo, e mesmo sendo insustentáveis tais atividades não podem ser mudadas, pois são elas que garantem a sobrevivência de um povo.

Assim como o Desenvolvimento sustentável, o conceito de Desenvolvimento Local (DL) pode ser visto sob diferentes aspectos que permitem conceituá-lo de diversas formas. De modo geral, o DL se caracteriza por cinco dimensões: "a Inclusão Social; o Fortalecimento e a Diversificação da Economia Local; a Inovação na Gestão Pública; a Proteção Ambiental e o Uso Racional de Recursos Naturais; e a Mobilização Social” (BROSE, 2010, p. 31). Seus conceitos variam de acordo com a linha de estudo de cada autor.

Para Milani (2003), Desenvolvimento Local é um conjunto de atividades culturais, econômicas, políticas e sociais, que participam de um projeto de transformação consciente da realidade local, sendo o desenvolvimento econômico uma variável essencial, mas não suficiente para se alcançar o desenvolvimento local.

Do mesmo ponto de vista de Milani (2010), Bandeira (2010) conceitua DL como uma grande estratégia para a melhoria de condições de vida, tal como geração de emprego e crescimento econômico, sendo este último visto de maneira integral, não deixando as necessidades sociais em segundo plano.

Para Buarque (1999), Desenvolvimento Local é um processo endógeno registrado em pequenas unidades territoriais e agrupamentos humanos capaz de promover o dinamismo econômico e a melhoria da qualidade de vida da população. Segundo o autor:

O desenvolvimento local é o resultado de múltiplas ações convergentes e complementares, capaz de quebrar a dependência e a inércia do subdesenvolvimento e do atraso em localidades periféricas e de promover uma mudança social no território. (BUARQUE, 1999, p.26)

Já Brose (2010) define DL como sendo não só um processo social, mas histórico, pois promove a melhoria da qualidade de vida da população de forma gradual em determinado território, seja ele uma comunidade, um município ou uma microrregião. Segundo ele:

\footnotetext{
O Desenvolvimento Local constituiria importante meio de combater a pobreza, promover maior inclusão social, além da geração de oportunidades de trabalho e renda. Por outro lado, o fortalecimento da democracia. O Desenvolvimento Local permitiria a ativa participação do cidadão, o efetivo controle social sobre a gestão pública através do fortalecimento da Sociedade Civil e o empoderamento de grupos sociais antes marginalizados nas esferas de tomada de decisão. (BROSE, 2010, pág. 1)
}

De forma mais simplificada Oliveira (2001) conceitua DL como aquele correspondente à noção de desenvolvimento humano, ou seja, à satisfação de um conjunto de requisitos de bem-estar e qualidade de vida. 
A partir dos diversos conceitos de Desenvolvimento Local, acima citados, podemos considerá-lo como um conjunto de ações que visam colocar em um mesmo patamar, as demandas sociais, políticas e econômicas, através de políticas públicas que promovam a satisfação de um conjunto de requisitos de bem-estar e melhoria da qualidade de vida da população.

\section{CONSIDERAÇÕES FINAIS}

No momento em que o sistema econômico criado pelo ser humano não é mais compatível com o sistema ecológico que a natureza oferece, existe a necessidade de uma nova adaptação das relações entre o Homem e a Natureza. Surge desta maneira a proposta da avaliação econômica do meio ambiente, que não tem como objetivo dar um "preço" a certo tipo de meio ambiente e sim mostrar o valor econômico que o meio ambiente pode oferecer e o prejuízo irrecuperável que pode haver caso seja destruído.

Para se alcançar o Desenvolvimento Sustentável não devemos levar em conta apenas as soluções técnicas, é preciso discutir as relações sociais entre homem e a sociedade, e as relações ambientais entre o homem e a natureza, pois tudo está sob a influência do homem. A natureza ou o meio ambiente jamais poderá ser pensado separadamente do homem, sendo este, parte integrante do meio ambiente e principal agente transformador do mesmo.

Quanto ao Ecodesenvolvimento, ele está por toda a parte, basta ser perceptível às potencialidades locais, ter criatividade e eficácia para tornar tais potencialidades em verdadeiros e poderosos agentes de desenvolvimento e crescimento econômico de forma sustentável.

Cabe ao leitor adotar o conceito de Desenvolvimento Sustentável ou Ecodesenvolvimento, já que ambos têm seu diferencial teórico podendo se adaptar a realidade e à abordagem do leitor. As divergências de alguns autores servem para ampliar nosso campo de conhecimento através das indagações. Onde realmente pretendemos chegar? E o Desenvolvimento sustentável é uma realidade a ser alcançada ou um verdadeiro mito? Essas são algumas de muitas questões que dificilmente terão uma resposta definitiva e que influenciam às diversas discussões acerca do tema.

\section{REFERÊNCIAS}

BANDEIRA, E. SANTOS, V. T. de A. Desenvolvimento Local: Sustentabilidade ou Subordinação? Disponível em: http://www.dge.uem.br. Acesso em: 17/08/2010.

BARBIERI, J. C. Desenvolvimento e meio ambiente: as estratégias da agenda $21.7^{\mathrm{a}}$ ed. Petrópolis: Vozes, 2005.

BROSE, M. Desenvolvimento local: uma conceituação empírica. Disponível em: http://www.lead.org.br. Acesso em: 17/08/2010.

Gestão Ambiental Empresarial: conceitos, modelos e instrumentos. São Paulo: Saraiva 2006.

BUARQUE, S. C. Metodologia de planejamento do desenvolvimento local e municipal sustentável. Brasília, junho de 1999. Disponível em: http://www.iica.org. br. Acesso em: 07/05/2010.

CARRERA, F. Cidade sustentável: utopia ou realidade? Rio de Janeiro: Lumen Juris, 2005.

CAVAlCANTI, C. (Org.). Desenvolvimento e Natureza: estudos para uma sociedade sustentável. São Paulo: Cortez; Recife: Fundação Joaquim Nabuco, 1995.

CHAVES, M. do P. S. R. RODRIGUES, D. C. B. R. Desenvolvimento sustentável: limites e perspectivas no debate contemporâneo. Interações (Campo Grande), Campo Grande, v. 8, n. 13, p. 99-106. 2006. 
DIAS, R. Gestão ambiental: responsabilidade social e sustentabilidade. São Paulo: Atlas, 2007

FALADORI, G. Limites do desenvolvimento sustentável. São Paulo: Editora da Unicamp, 2001.

FERREIRA, B. de H. Miniaurélio Século XXI Escolar: O minidicionário da língua portuguesa. Rio de Janeiro: Nova Fronteira, 2000.

FREY, K. A dimensão político-democrática nas teorias de desenvolvimento sustentável e suas implicações para a gestão local. Ambiente e Sociedade. Campinas, n. 9, dez. 2001. Disponível em: http://www. scielo.br. Acesso em: 07/05/2012.

FURTADO, C. O Capitalismo Global. São Paulo: Paz e Terra, 1998.

GUARAGNI, M. V.; CARON, A. O novo papel do estado como ator do processo de desenvolvimento sustentável. Disponível em: www.unifae.br. Acesso em: 01/05/2012.

JACOBI, P. Poder local, políticas sociais e sustentabilidade. Saúde sociedade. São Paulo, v. 8, n. 1, fev. 1999.

MATIAS, H. J. D.; PINHEIRO, J. de Q. Desenvolvimento sustentável: um discurso sobre a relação entre desenvolvimento e natureza. Psicol. Soc., Porto Alegre, v. 20, n. 1, abr. 2008.

MENEGAT, R.; ALMEIDA, G.(orgs). Desenvolvimento sustentável e gestão ambiental nas cidades: estratégias a partir de Porto Alegre. Porto Alegre: Editora da UFRGS, 2004.

MILANI, C. Teorias do Capital social e desenvolvimento local: loções a partir da experiência de Pitandas (Bahia, Brasil). 2003. Disponível em: http://new.lasociedadcivil.org. Acesso em: 08/06/ 2010.

MONTIBELLER FILHO, G. O mito do desenvolvimento sustentável: meio ambiente e custos sociais no moderno sistema de produtor de mercadorias. $2^{\mathrm{a}}$ ed. Florianópolis: Ed. da UFSC, 2004.

OLIVEIRA, F. de. Aproximações ao enigma: o que quer dizer desenvolvimento local? São Paulo, Pólis; Programa Gestão Pública e Cidadania / EAESP / FGV, 2001. 40p. Disponível em: http://www.polis.org.br. Acesso em: 08/11/2009.

OMENA NETO, A. J. de. A energia e o desenvolvimento do Estado de Alagoas. Revista de Economia Política do Desenvolvimento Maceió, vol. 1, n. 7, p. 123-149, jan./abr. 2010.

SACHS, I. Ecodesenvolvimento crescer sem destruir. Terra dos Homens. $1^{\text {a }}$ ed. São Paulo: Editora Vértice, 1986, 207p.

Desenvolvimento includente, sustentável, sustentado. Rio de Janeiro: Garamond, 2004.

SOUZA, M. L. de. O desafio metropolitano: um estudo sobre a problemática sócio-espacial nas metrópoles brasileiras. $2^{\mathrm{a}}$ ed. Rio de Janeiro: Bertrand Brasil, 2005.

VEIGA, J. E. da. Desenvolvimento Sustentável: O desafio do século XXI. Rio de Janeiro: Garamond, 2005. 